\title{
Dynamics of ammonia-oxidizing archaea and bacteria populations and contributions to soil nitrification potentials
}

\author{
Anne E Taylor ${ }^{1}$, Lydia H Zeglin ${ }^{1}$, Thomas A Wanzek ${ }^{1}$, David D Myrold ${ }^{1}$ and Peter J Bottomley ${ }^{1,2}$ \\ ${ }^{1}$ Department of Crop and Soil Science, Oregon State University, Corvallis, OR, USA and ${ }^{2}$ Department of \\ Microbiology, Oregon State University, Corvallis, OR, USA
}

\begin{abstract}
It is well known that the ratio of ammonia-oxidizing archaea (AOA) and bacteria (AOB) ranges widely in soils, but no data exist on what might influence this ratio, its dynamism, or how changes in relative abundance influences the potential contributions of $A O A$ and $A O B$ to soil nitrification. By sampling intensively from cropped-to-fallowed and fallowed-to-cropped phases of a 2-year wheat/ fallow cycle, and adjacent uncultivated long-term fallowed land over a 15-month period in 2010 and 2011, evidence was obtained for seasonal and cropping phase effects on the soil nitrification potential (NP), and on the relative contributions of AOA and AOB to the NP that recovers after acetylene inactivation in the presence and absence of bacterial protein synthesis inhibitors. AOB community composition changed significantly $(P \leqslant 0.0001)$ in response to cropping phase, and there were both seasonal and cropping phase effects on the amoA gene copy numbers of AOA and AOB. Our study showed that the AOA:AOB shifts were generated by a combination of different phenomena: an increase in AOA amoA abundance in unfertilized treatments, compared with their AOA counterparts in the $\mathrm{N}$-fertilized treatment; a larger population of $A O B$ under the $\mathrm{N}$-fertilized treatment compared with the $A O B$ community under unfertilized treatments; and better overall persistence of AOA than AOB in the unfertilized treatments. These data illustrate the complexity of the factors that likely influence the relative contributions of AOA and AOB to nitrification under the various combinations of soil conditions and $\mathrm{NH}_{4}^{+}$-availability that exist in the field.
\end{abstract}

The ISME Journal (2012) 6, 2024-2032; doi:10.1038/ismej.2012.51; published online 14 June 2012

Subject Category: microbial population and community ecology

Keywords: ammonia; archaea; bacteria; nitrification; soil

\section{Introduction}

Ammonia-oxidizing archaea (AOA) and ammoniaoxidizing bacteria (AOB) co-occupy every agricultural soil that has been examined to date. However, we know little about AOA and AOB population dynamics under field conditions, or how their relative contributions to soil nitrification respond to the combination of cropping treatment and seasonal conditions. It has been observed in laboratory incubations that AOB amoA gene abundance increases in soils supplemented with high levels of $\mathrm{NH}_{4}^{+}$(200-400 $\mu \mathrm{g} \mathrm{Ng}^{-1}$ soil) (Jia and Conrad, 2009; Verhamme et al., 2011), whereas AOA amoA gene abundance increases in soil incubations where $\mathrm{NH}_{4}^{+}$ was supplied endogenously from mineralization of organic matter or added in low concentrations ( $\leqslant 20 \mu \mathrm{g} \mathrm{Ng}^{-1}$ soil) (Offre et al., 2009; Zhang et al.,

Correspondence: AE Taylor, Department of Crop and Soil Science, Oregon State University, 3017 Ag Life Science Building, Corvallis, OR 97331, USA

E-mail: anne.taylor@oregonstate.edu

Received 19 January 2012; revised 28 March 2012; accepted 30 March 2012; published online 14 June 2012
2010; Verhamme et al., 2011). In a previous study, we developed an assay that allows us to determine the relative contributions of bacteria and archaea to the nitrification potential (NP) of soil slurries (Taylor et al., 2010). It was shown that whereas the NP of permanent pasture soils was dominated by AOA, the NP of N-fertilized cultivated soils under wheat was dominated by AOB, and, that both AOA and $\mathrm{AOB}$ contributed to the NP of long-term fallowed soils (no tillage or $\mathrm{N}$ fertilizer for 19 years) (Taylor et al., 2010). Collectively, these observations suggest that AOA and AOB may occupy different soil niches perhaps controlled by $\mathrm{NH}_{4}^{+}$availability.

In most cropping systems, $\mathrm{N}$ fertilization results in a transient pulse of high $\mathrm{NH}_{4}^{+}$concentrations, that is followed by a much longer period of lower $\mathrm{NH}_{4}^{+}$availability dependent on N-mineralization from soil and crop residues (Shi et al., 2004; Norton, 2008). A case can be made that the relative contributions of AOA and AOB to soil nitrification might shift in different phases of crop rotation and during different seasons of the year. Although recent studies have evaluated AOA and AOB population sizes, composition and/or their relative growth responses 
in soils recovered from agricultural cropping systems, the soils were often taken from complex crop rotations in multi-year cycles, and sampled in either spring, fall or unspecified times (Tourna et al., 2008; Hallin et al., 2009; Wessen et al., 2010, 2011; Xia et al., 2011). Clearly, the extent to which phase of the crop rotation or time of soil sampling might have influenced the results cannot be determined.

We have chosen a simple 2-year cropping cycle of winter wheat/fallow to test our hypothesis that environmental conditions combined with shifts in $\mathrm{NH}_{4}^{+}$availability will influence the dynamics of $\mathrm{AOA}$ and $\mathrm{AOB}$ contributions to nitrification. We hypothesized that the relative success of AOA and AOB through the 2-year cropped/fallowed cycle will depend upon a combination of the following: (a) differential growth responses of $\mathrm{AOA}$ and $\mathrm{AOB}$ to the application of fertilizer $\mathrm{NH}_{4}^{+}-\mathrm{N}$; and (b) differential abilities of the AOA and AOB populations to survive the $\mathrm{NH}_{4}^{+}$limiting conditions that exist over the majority of the 2-year cropping cycle, and the associated seasonal shifts in soil conditions.

\section{Materials and methods}

Chemicals

$\mathrm{N}$-tris[hydroxymethyl]methyl-2-aminoethanesulfonic acid (TES) buffer, neomycin trisulfate salt and $\mathrm{NH}_{4} \mathrm{Cl}$ were obtained from Sigma (St Louis, MO, USA). Acetylene was obtained from Airgas (Radnor, PA, USA). Kanamycin sulfate and gentamycin sulfate were obtained from EMD Biosciences, Inc. (La Jolla, CA, USA). Szechrome NAS was obtained from Polysciences, Inc. (Warrington, PA, USA).

\section{Soils}

Soil samples were collected monthly or bimonthly from fields at the Oregon State University Hyslop Field Research Laboratory located $16 \mathrm{~km}$ north of Corvallis, Oregon (see Supplementary Information for more details about the study site). Beginning in April 2010, we sampled three cropped-to-fallowed fields (CF), which were planted in winter wheat Oct 2009 , fertilized with urea (150 $\mathrm{kg} \mathrm{NH}_{4}^{+}-\mathrm{N}$ per acre) in Feb 2010, harvested in Aug 2010, fallowed until Oct 2011, and then replanted to wheat. Three fallowedto-cropped fields (FC) were sampled, which had grown wheat in 2009, and were fallowed through most of 2010, tilled and planted to wheat in Oct 2010 and fertilized with $150 \mathrm{~kg} \mathrm{NH}_{4}^{+}-\mathrm{N}$ per ha (a combination of urea and $\left.\left(\mathrm{NH}_{4}\right)_{2} \mathrm{SO}_{4}\right)$ in Mar 2011. Three long-term fallow fields (LTF) were sampled, which had not been cropped, fertilized or tilled since 1990 and were colonized by volunteer grasses and forbs, and are mowed twice yearly. Four to five soil samples were recovered to a depth of $10 \mathrm{~cm}$ from each field via a random walk process, composited and thoroughly mixed, and brought to the laboratory where it was sieved $(4.75 \mathrm{~mm})$ and stored at $4{ }^{\circ} \mathrm{C}$ (Peterson and Calvin, 1996). Samples of soil $(5-10 \mathrm{~g})$ were oven-dried at $105^{\circ} \mathrm{C}$ to determine the water content. $2 \mathrm{M} \mathrm{KCl-extractable} \mathrm{NH}_{4}^{+}$was determined at the Central Analytical Services Laboratory, Department of Crop and Soil Science, Oregon State University by continuous flow analysis using an Alpkem RFA 300 auto-analyzer (Astoria Pacific, Clackamas, OR, USA). Precipitation and soil temperature $(0-10 \mathrm{~cm})$ data are recorded daily at Hyslop Farm (http://cropandsoil.oregonstate.edu/weather).

\section{Nitrification potential}

NPs with $1 \mathrm{mM} \mathrm{NH}_{4} \mathrm{Cl}$ were determined on soil samples within a week of each sampling time as described previously (Taylor et al., 2010). NP rates were determined as nitrite $\left(\mathrm{NO}_{2}^{-}\right)$plus nitrate $\left(\mathrm{NO}_{3}^{-}\right)$ accumulated over $24 \mathrm{~h}$ per g of oven dry soil. An acetylene-containing control was also included to ensure that all nitrification activity was acetylene sensitive. See Supplementary Information for additional experimental description.

\section{Recovery of nitrification potential}

The details of the RNP assay are described in detail in Supplementary Information. Briefly, acetylene inhibition and RNP steps were carried out at $30^{\circ} \mathrm{C}$ with $1 \mathrm{~mm}$ supplemental $\mathrm{NH}_{4}^{+}$(Taylor et al., 2010). Acetylene was removed by degassing the soil slurries for 6 min. RNPs in the absence of inhibitors were considered to be the standard $\left(\mathrm{RNP}_{\text {total }}\right)$. In some treatments, the bacterial protein synthesis inhibitor kanamycin was added at a final concentration of $800 \mu \mathrm{g} \mathrm{ml}^{-1}$ to prevent resynthesis of ammonia monooxygenase (AMO) by AOB. Any RNP that recovers in the presence of a bacterial protein synthesis inhibitor is likely to be contributed by AOA $\left(\mathrm{RNP}_{\mathrm{AOA}}\right)$. $\mathrm{RNP}_{\text {total }}-\mathrm{RNP}_{\mathrm{AOA}}$ is determined to be the contribution of AOB to RNP ( $\left.\mathrm{RNP}_{\mathrm{AOB}}\right)$.

\section{Nucleic acid analysis}

Extraction of nucleic acids. Samples of freshly collected and sieved soils for DNA extraction were stored at $-20^{\circ} \mathrm{C}$. DNA was extracted from frozen samples using a MoBio PowerSoil (Carlsbad, CA, USA) extraction kit, and DNA quantified using a NanoDrop ND-1000 UV-vis Spectrophotometer (ThermoScientific, Rockwood, TN, USA). Quantifiable DNA was extracted from every soil sample, with higher DNA yields recovered from soils of the LTF $(12.9 \pm 4.0 \mu \mathrm{g}$ per g soil) than from soils of the CF and FC treatments $(4.4 \pm 2.6 \mu \mathrm{g}$ per g soil).

Quantitative PCR of the archaeal and bacterial amoA genes. Quantitative PCR (QPCR) of the AOA and AOB amoA genes was performed using the HotStart-IT SYBR Green qPCR Master Mix (USB, Santa Clara, CA, USA) and an ABI 7500 Real 
Time PCR System (Foster City, CA, USA). Each $20 \mu \mathrm{l}$ reaction volume included $1 \mathrm{ng}$ template DNA. Primers CrenamoA23f and CrenamoA616r (Tourna et al., 2008) were used to quantify AOA amoA gene abundance. Primers (amoA_1R and amoA_2F) and thermal cycler protocols for bacterial amoA genes are described elsewhere (Rotthauwe et al., 1997). Standard curves were constructed with $4.6 \times 10^{1}$ to $4.6 \times 10^{-4} \mathrm{ng}$ Nitrosomonas europaea genomic DNA (bacterial amoA, efficiency $=98 \pm 9 \%, R^{2}$ avg $=$ $0.97 \pm 0.02$ ) or $54.1 \times 10^{0}$ to $5.41 \times 10^{-5} \mathrm{ng}$ of 'Candidatus nitrosopumilus maritimus' strain SCM1 genomic DNA (efficiency $=105 \pm 8 \%, R^{2}$ avg $=$ $0.97 \pm 0.01)$. Archaeal amoA standards were also constructed with a TOPO plasmid containing the 'Candidatus Nitrosopumilus maritimus' strain SCM1 amoBAC gene insert to confirm the results obtained with genomic DNA standards. Each reaction was run in triplicate. Copy numbers were standardized to the mass of DNA extracted per g oven dry soil.

$A O A$ and $A O B$ community composition analysis. For terminal restriction fragment length polymorphism assays, archaeal and bacterial amoA, primer pairs (Arch amoAf/Arch amoAr, and amoA 1F/ amoA 2R), with the forward primer 5'-end 6-FAMlabeled were used to produce PCR products from soil samples of the three field replicates of each treatment on six sampling occasions (May, Jul, Oct and Dec 2010, Feb and May 2011). PCR products were purified using a UltraClean PCR Clean-up DNA Purification Kit (Mo Bio, Carlsbad, CA, USA), and restricted with either CfoI, AluI or TaqI for the bacterial amoA gene analysis (Horz et al., 2000; Mintie et al., 2003), and with RsaI and MspI for the archaeal amoA gene analysis (Boyle-Yarwood et al., 2008). The digests were purified and fragment lengths and relative abundances were analyzed using an ABI 3100 capillary sequencer and Genotyper 3.7 (Foster City, CA, USA). For each sample, any fragments comprising $<5 \%$ of relative total fluorescence were removed from subsequent analysis. The relative fluorescence abundances of unique terminal restriction fragments (T-RFs) were exported for further analysis.

\section{Statistics}

Repeated-measures analysis of variance was used to test whether treatment or sampling time had a significant effect on NP and RNP rates, or AOA and AOB amoA abundances. In the case of amoA abundances, data were log transformed to meet normality assumptions. Analysis was done with PROC MIXED using a Banded Toeplitz covariance model and least squares means for treatment comparisons (SAS Institute, Inc., Cary, NC, USA). Because the treatment by time interaction was significant for all response variables, the significance of treatments were evaluated at each sampling time and the significance of temporal differences were evaluated within each treatment. The TukeyKramer adjustment for multiple comparisons was used to control experiment-wise error rates, with $P \leqslant 0.05$ chosen to denote significant differences. Complete summaries of the repeated-measures analyses of variance are contained in Supplementary Tables S1 and S2. A $t$-test was used to evaluate the significant difference between $\mathrm{NP}$ and $\mathrm{RNP}_{\text {total }}$ $(P \leqslant 0.05)$, and also between $\mathrm{RNP}_{\mathrm{AOA}}$ and $\mathrm{RNP}_{\mathrm{AOB}}$ for a few selected sampling times within a treatment.

The structure of the AOA and AOB community composition was investigated with non-metric multidimensional scaling. Matrices were constructed for the AOA community containing the combined MspI and RsaI T-RFs, and the AOB community matrix containing the combined $C f o \mathrm{I}$ and AluI T-RFs. Multiple response permutation procedure was used to test for treatment and temporal differences in community composition. Non-metric multidimensional scaling and multiple response permutation procedure were performed using PC-ORD (McCune and Mefford, 1999).

\section{Results}

Characterization of study site

Corvallis, OR has cool wet winters and warm dry summers, which is reflected in the metadata shown in Figures 1a and b. During this study soil temperatures ranged from $1.7^{\circ} \mathrm{C}$ (Jan 2010) to $42.8^{\circ} \mathrm{C}$ (Jul 2010), and total precipitation was $>190 \mathrm{~cm}$, with little rain falling during the summer months. Soils in LTF retained more water (0.18-0.38g per g soil, Figure 1b) than the CF and FC soils (0.09-0.24g per g soil) from Apr 2010 to Aug 2010. CF and FC soils were water saturated from Oct 2010 to May 2011, whereas the betterstructured LTF soils were unsaturated. CF soils were $\mathrm{N}$ fertilized in mid Feb 2010, and FC soils were fertilized in mid Mar 2011, each with $150 \mathrm{~kg} \mathrm{NH}_{4}^{+}-\mathrm{N}$ per ha; however, by May 2010 (CF) and May 2011 (FC), extractable $\mathrm{NH}_{4}^{+}$levels had returned to the levels in unfertilized soils (Figure 1c). There was a trend for LTF soils to contain a higher level of extractable $\mathrm{NH}_{4}^{+}-\mathrm{N}$ than the $\mathrm{CF}$ or FC soils at all sample times with the exception of the first sampling time post $\mathrm{N}$ fertilization (Apr 2010 and Apr 2011). $\mathrm{NH}_{4}^{+}-\mathrm{N}$ accumulated in all three soil treatments between Oct and Dec 2010 before declining in Jan and Feb 2011. During $2010 \mathrm{NO}_{3}^{-}$ accumulated in both the CF and FC treatments between Jun and Oct 2010 and reached a higher level in FC than in CF (Figure 1d). High extractable $\mathrm{NO}_{3}^{-}$concentrations were also measured in FC soils in Apr 2011, yet had declined below the level of detection by May 2011.

Cropping phase and seasonal effects on NP activities The seasonal dynamics of NPs with $1 \mathrm{mM}$ supplemental $\mathrm{NH}_{4}^{+}$are shown in Figure 2 . 

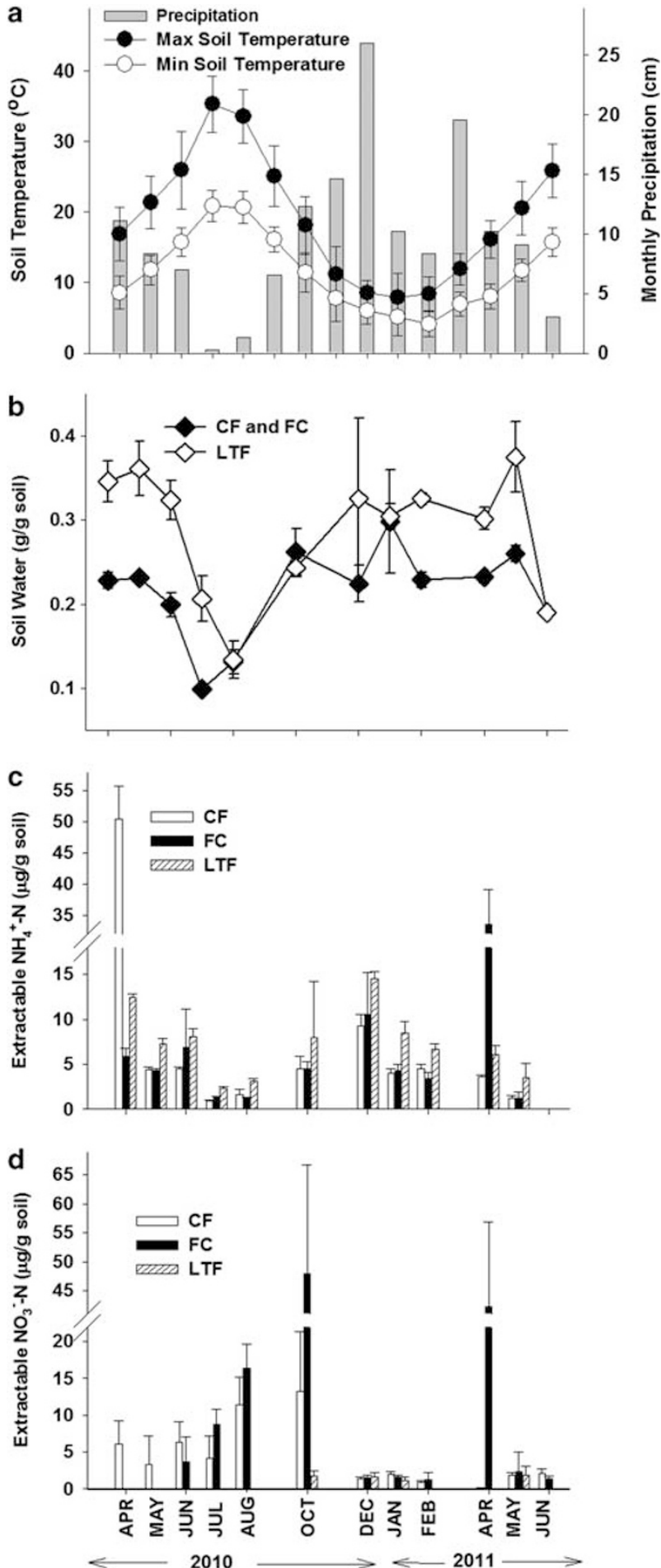

Figure 1 Soil temperature, water content and mineral-N profiles of CF, FC and LTF treatments during the study period. (a) Monthly precipitation amounts (cm of rainfall) and average minimum and maximum soil temperatures at a depth of $0-10 \mathrm{~cm}$. Error bars represent s.d. of the monthly temperature average. (b) Average soil water content of the three treatments. CF and FC treatments maintained the same soil water contents and each sample time represents an average of the three field replicates from each treatment. The open symbols represent the average of three field replicates from LTF. (c) Average KCl-extractable $\mathrm{NH}_{4}^{+}-\mathrm{N}$ of three field replicates per treatment. (d) Average extractable $\mathrm{NO}_{3}^{-}-\mathrm{N}$ of three field replicates per treatment. Error bars represent s.d. of average.

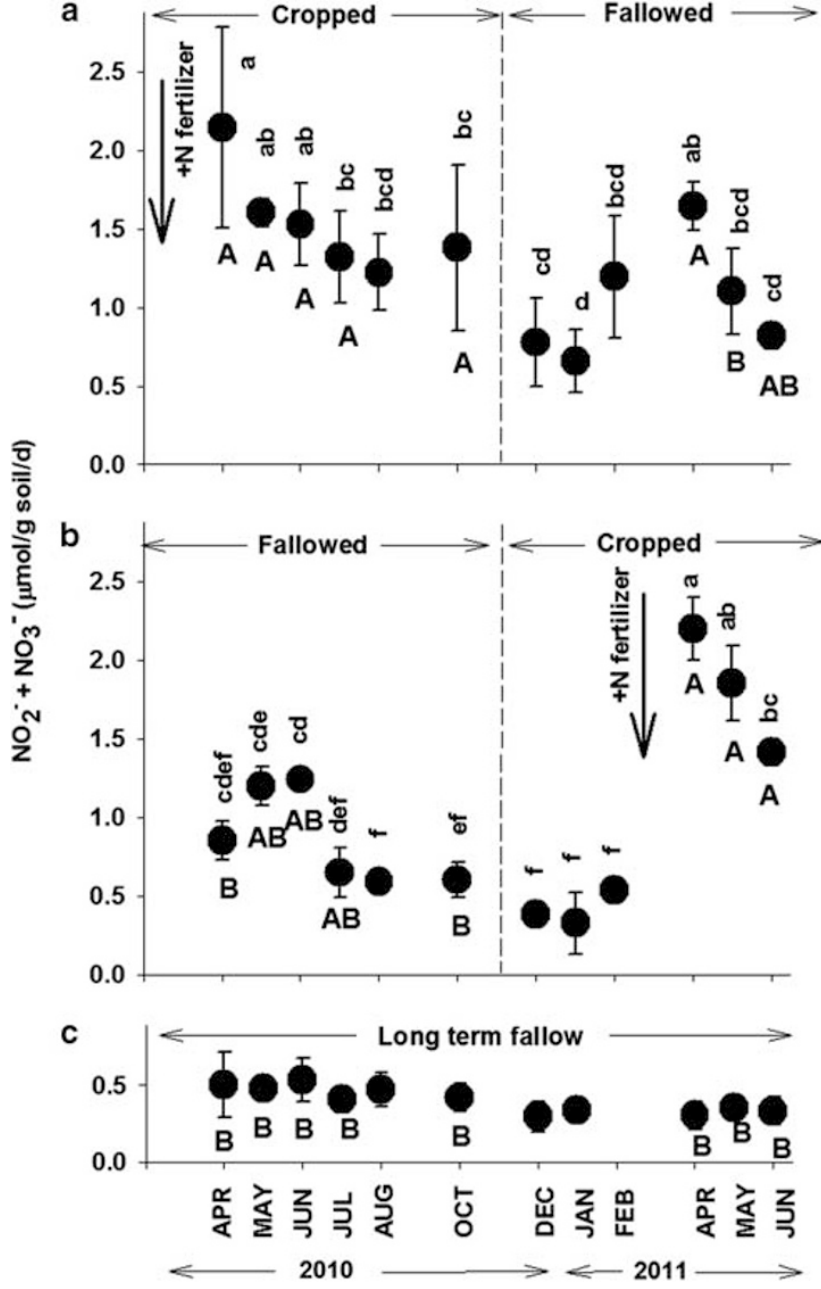

Figure 2 Effects of cropping phase treatment and sampling time on the NP rates with $1 \mathrm{~mm}$ supplemental $\mathrm{NH}_{4}^{+}$in $\mathrm{CF}(\mathbf{a}), \mathrm{FC}(\mathbf{b})$ and LTF (c) treatments. Bold vertical arrows indicate field applications of 150-kg N fertilizer to CF (Feb 2010) and FC (Mar 2011) treatments. Error bars represent s.d. of the average NP of three field replicates from each treatment. Lower case letters indicate significance $(P \leqslant 0.05)$ of sampling time within a specific treatment. Values that have lower case letters in common are not significantly different. The absence of lower case letters in LTF indicates no significant difference within sampling times in this treatment. Upper case letters indicate significance $(P \leqslant 0.05)$ between different treatments at the same sampling time. Values that have upper case letters in common are not significantly different. The absence of an upper case letter (Aug, Dec, Jan and Feb) indicates no significant difference between treatments at the same sampling time. See experimental procedures for further details of the statistical analyses.

Cropped/Fallowed (CF). NP rates in CF were highest at the first post $\mathrm{N}$ fertilization sampling in Apr 2010 (Figure 2a), and declined significantly ( 50\%) by Jul 2010. The lowest rate of NP occurred during Jan 2011. In Apr 2011, NP in CF had increased significantly ( $\sim 2$-fold) above the Jan minimum value, even though this sample was taken 14 months post fertilizer $\mathrm{N}$ addition. Subsequently, the NP dropped significantly by Jun 2011 .

Fallowed/Cropped (FC). Although FC had not received $\mathrm{N}$ fertilizer since February 2009, (14 months 
prior to the start of this study), there was a trend for NP to increase non-significantly between Apr 2010 and May/Jun 2010 (Figure 2b). This was followed by a significant two-fold decline in NP between Jun and Aug. The lowest NP rates were observed during Dec 2010 through Feb 2011. After $\mathrm{N}$ fertilization in mid Mar 2011, the NP increased significantly and peaked in Apr at a value $\sim 4$-fold greater than the pre-N fertilization rate in Feb, and was significantly greater than the highest NP rates measured in May and June of the previous year (2010) in the fallowed phase.

Long-term fallow. In contrast to the seasonal influences detected in the NPs of CF and FC, NP rates in LTF did not change significantly during the course of the study (Figure 2c). Rates of NP in LTF were significantly less than the highest values

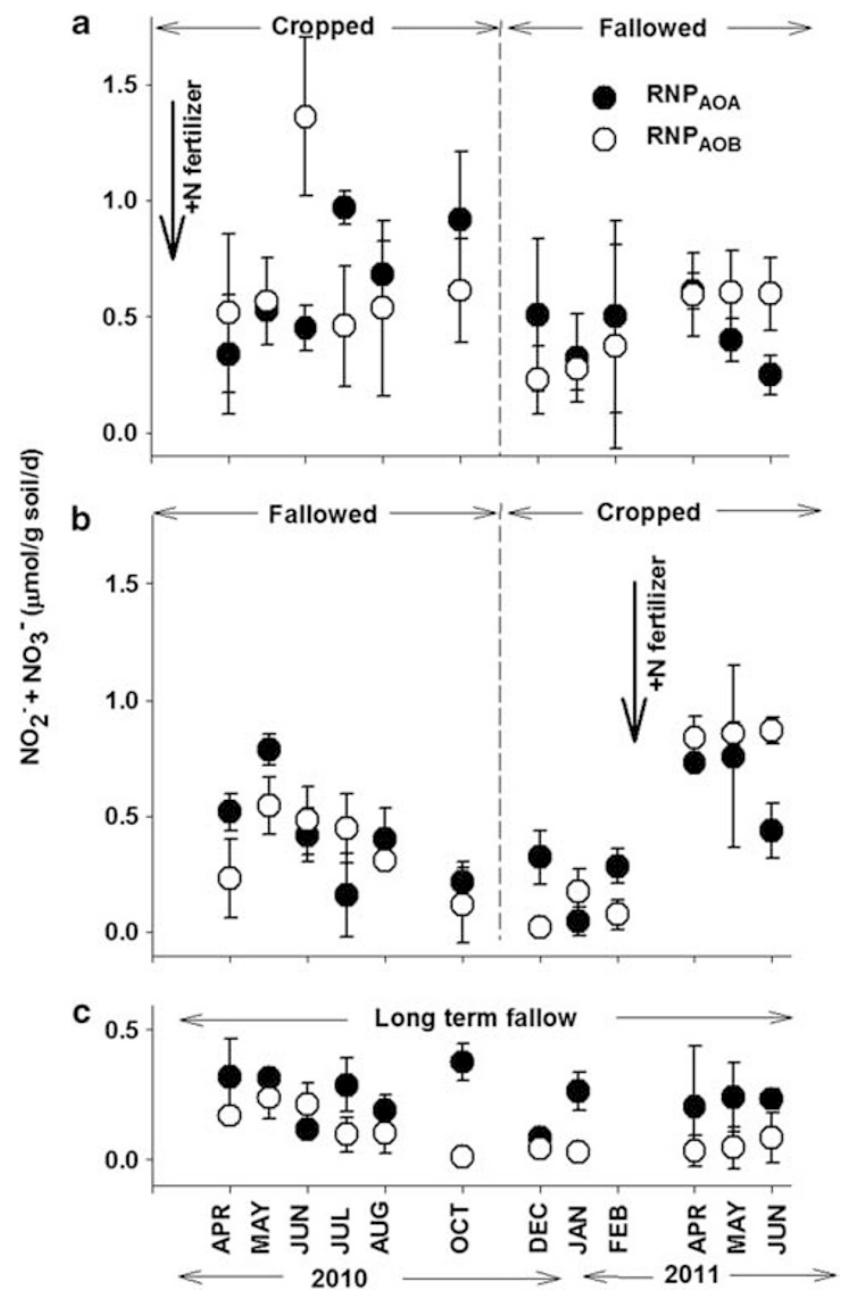

Figure 3 Effects of cropping phase treatment and sampling time on the recovered nitrification potential (RNP) rates contributed by AOA and AOB in CF (a), FC (b) and LTF (c) treatments. Bold arrows indicate field applications of $\mathrm{N}$ fertilizer (see Figure 2). Error bars represent the s.d. of the average RNP of three field replicates from each treatment. A complete summary of the statistical analysis of these data is shown in Supplementary Table S1. measured during the cropping phase post $\mathrm{N}$ fertilization in either CF (Apr 2010-Oct 2010) or FC (Apr 2011-Jun 2011); but, with one exception (CF, Apr 2011), they were not significantly different from the fallowed phase NP rates of CF (Dec $2010-$ Jun 2011) and FC (Apr 2010-Feb 2011), despite LTF having received no $\mathrm{N}$ fertilizer for 20-21 years.

Cropping phase and seasonal effects on the RNP

The seasonal dynamics of RNP were determined for each of the three field replicates of CF, FC and LTF at each of the sampling times (Figure 3). In most cases, $\mathrm{RNP}_{\text {total }}$ rates were not significantly different $(P \leqslant 0.05)$ than the rates of the NPs, suggesting that the same populations of ammonia oxidizers contributed to both NP and RNP.

Cropped/Fallowed (CF). Both AOA and AOB contributed to RNP at all sampling times indicating the potential of both groups of microorganisms to contribute to ammonia oxidation across all phases and seasons of CF (Figure 3a). Curiously, RNP total was significantly lower than NP in Apr and May 2010, and in Apr 2011 when NPs were at their highest values. The rates of $\mathrm{RNP}_{\text {total }}$ were highest in Jun 2010, 3 months after $\mathrm{N}$ fertilization, and lowest during Jan 2011. There was a trend for the highest rates of $\mathrm{RNP}_{\mathrm{AOA}}$ to occur in Jul through Oct 2010. In one case (Jul 2010), $\mathrm{RNP}_{\mathrm{AOA}}$ was significantly greater $(P \leqslant 0.05)$ than $\mathrm{RNP}_{\mathrm{AOB}}$ (Table 1$)$. Rates of $\mathrm{RNP}_{\mathrm{AOB}}$ were significantly higher in Jun 2010 than at any other time (Supplementary Table S1), and were significantly greater $(P \leqslant 0.05)$ than rates of $\mathrm{RNP}_{\mathrm{AOA}}$ in both Jun 2010 and Jun 2011. There were no

Table 1 A summary of the relative contributions of $\mathrm{RNP}_{\mathrm{AOB}}$ to $\mathrm{RNP}_{\text {total }}$ in CF, FC and LTF treatments

\begin{tabular}{|c|c|c|c|}
\hline \multirow{2}{*}{$\begin{array}{l}\text { Sample } \\
\text { Time }\end{array}$} & \multicolumn{3}{|c|}{$R N P_{A O B} / R N P_{\text {total }}$} \\
\hline & $C F$ & $F C$ & $L T F$ \\
\hline Apr 2010 & $0.60(0.25)$ & $0.29(0.17)^{*}$ & $0.37(0.14)$ \\
\hline May 2010 & $0.51(0.10)$ & $0.41(0.07)^{*}$ & $0.42(0.10)$ \\
\hline Jun 2010 & $0.75(0.04)^{*}$ & $0.53(0.05)$ & $0.63(0.09)$ \\
\hline Jul 2010 & $0.31(0.12)^{*}$ & $0.75(0.24)^{*}$ & $0.27(0.20)^{*}$ \\
\hline Aug 2010 & $0.41(0.20)$ & $0.45(0.08)$ & $0.34(0.20)$ \\
\hline Oct 2010 & $0.40(0.14)$ & $0.28(0.35)$ & $0.02(0.04)^{*}$ \\
\hline Dec 2010 & $0.36(0.25)$ & $0.08(0.14)^{*}$ & $0.28(0.25)$ \\
\hline Jan 2011 & $0.48(0.17)$ & $0.94(0.32)$ & $0.11(0.11)^{*}$ \\
\hline Feb 2011 & $0.40(0.44)$ & $0.18(0.11)^{*}$ & - \\
\hline Apr 2011 & $0.49(0.07)$ & $0.54(0.06)$ & $0.33(0.57)$ \\
\hline May 2011 & $0.60(0.05)$ & $0.55(0.11)$ & $0.17(0.29)^{*}$ \\
\hline Jun 2011 & $0.70(0.11)^{*}$ & $0.67(0.04)^{*}$ & $0.23(0.21)$ \\
\hline
\end{tabular}

Abbreviations: AOA, ammonia-oxidizing archaea; AOB, ammoniaoxidizing bacteria; CF, cropped-to-fallowed; FC, fallowed-to-cropped; LTF, long-term fallow; RNP, recovery of nitrification potential. Values in parentheses represent the s.d. of the average of $\mathrm{RNP}_{\mathrm{AOB}} /$ $\mathrm{RNP}_{\text {total }}$ of each of the three field replicates. Asterisks indicate the times when the rates of $\mathrm{RNP}_{\mathrm{AOA}}$ and $\mathrm{RNP}_{\mathrm{AOB}}$ of a specific treatment were significantly different as determined by a $t$-test $(P \leqslant 0.05)$. 
significant differences in the rates of $\mathrm{RNP}_{\mathrm{AOB}}$ of the remaining samples.

Fallowed/Cropped (FC). The highest rates of $\mathrm{RNP}_{\text {total }}$ in FC were measured in Apr and May 2011, after $\mathrm{N}$ fertilization in Mar (Figure $3 \mathrm{~b}$ ) and the lowest rate occurred in Jan 2011. During the fallowed phase in 2010, the maximum rate of $\mathrm{RNP}_{\mathrm{AOA}}$ occurred in May and was lowest in Jan 2011. At four sampling times prior to $\mathrm{N}$ fertilization (Apr, May and Dec 2010, and Feb 2011), the rate of $\mathrm{RNP}_{\mathrm{AOA}}$ was significantly greater than the rate of $\mathrm{RNP}_{\text {AOB }}(P \leqslant 0.05$, Table 1$)$. After $\mathrm{N}$ fertilization in Mar 2011, rates of $\mathrm{RNP}_{\mathrm{AOA}}$ were significantly greater in Apr and May than in Jan 2011 (Supplementary Table S1). In 2010, the $\mathrm{RNP}_{\mathrm{AOB}}$ rate was also greatest in May and declined significantly by Dec 2010. There was a significant increase in the rates of $\mathrm{RNP}_{\text {Аов }}$ in Apr through June 2011 after $\mathrm{N}$ fertilization in Mar 2011. In only two samples (Jul 2010 and Jun 2011), were the rates of $\mathrm{RNP}_{\mathrm{AOB}}$ significantly greater than the rates of $\mathrm{RNP}_{\mathrm{AOA}}(P \leqslant 0.05)$.

Long-term fallow. $\mathrm{RNP}_{\text {total }}$ was no different than NP except in Aug and Dec 2010. Rates of $\mathrm{RNP}_{\mathrm{AOA}}$ did not change significantly over the study (Figure 3c, Supplementary Table S1) and were similar in magnitude to all values of $\mathrm{RNP}_{\mathrm{AOA}}$ measured in $\mathrm{FC}$, and to the majority of the rates in CF (except during Jul and Oct 2010). Rates of $\mathrm{RNP}_{\mathrm{AOA}}$ were significantly greater than rates of $\mathrm{RNP}_{\mathrm{AOB}}$ in Jul 2010, Oct 2010, Jan 2011 and May 2011 (Table 1). In LTF there were no significant differences in rates of $\mathrm{RNP}_{\mathrm{AOB}}$ over the course of the study. However, there was a trend for rates of $\mathrm{RNP}_{\mathrm{AOB}}$ to be highest between Apr and Aug 2010 when they contributed more to $\mathrm{RNP}_{\text {total }}$, and which corresponded with the highest NPs. Rates of $\mathrm{RNP}_{\mathrm{AOB}}$ were significantly lower than the highest values recorded for $\mathrm{CF}$ and FC (Jun and Oct 2010 in CF, and Apr, May and Jun 2011 in FC).

$A O A$ and $A O B$ population dynamics in response to cropping phase and season

With QPCR we compared the sizes of AOA and AOB populations using amoA gene copy number as a surrogate for AOA and AOB abundance (Figure 4). AOA and AOB amoA were successfully quantified in every sample.

AOA. AOA amoA gene copies ranged from being numerically similar to AOB amoA gene copies, to two orders of magnitude more abundant (Figure 4). From Apr through Dec 2010, there were no significant differences in the AOA amoA gene copy abundances among the three treatments (Supplementary Table S2), and the population densities averaged $3.2 \pm 2.1 \times 10^{7}$ amoA copy numbers per g soil. In all treatments, the lowest AOA amoA copy numbers were measured in Jan 2011,

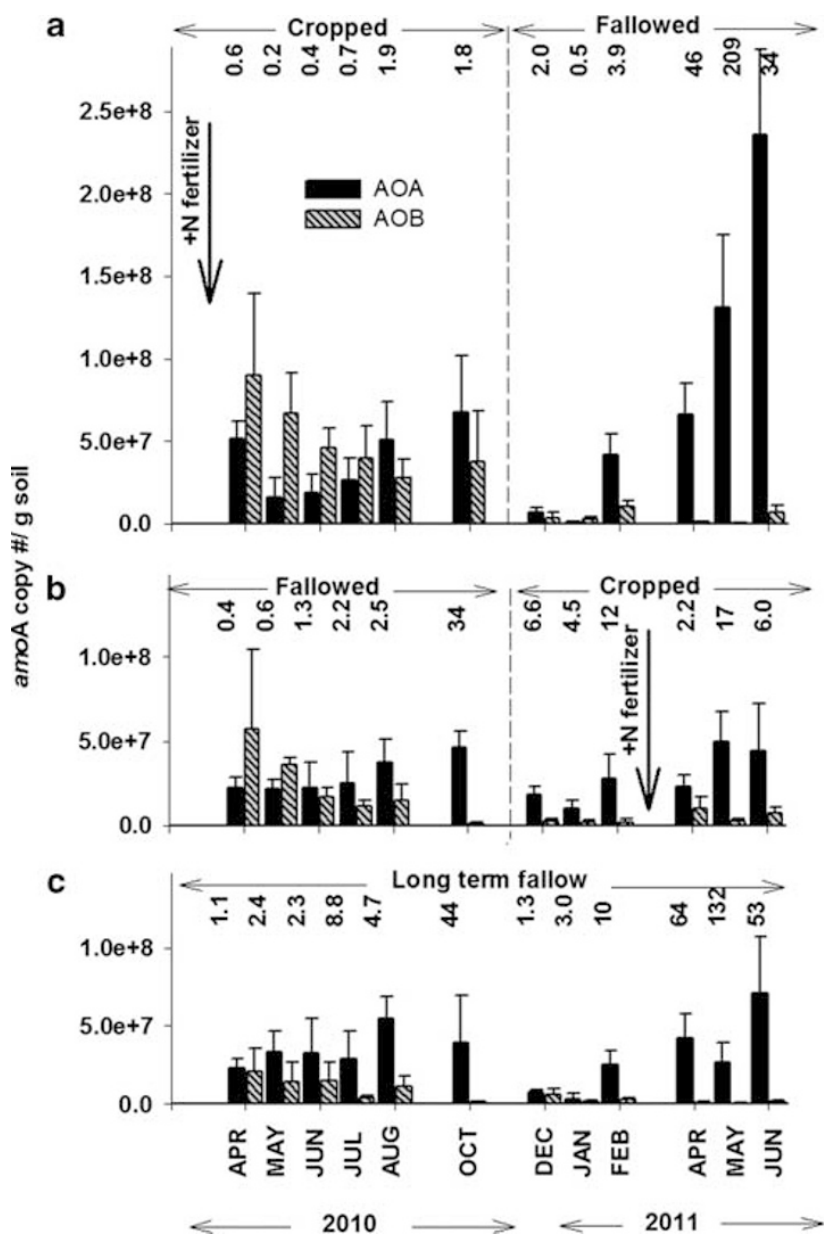

Figure 4 Effects of cropping phase treatment and sampling time on the AOA and AOB amoA copy number per g soil in CF (a), FC (b) and LTF (c) treatments. Bold arrows indicate field applications of $\mathrm{N}$ fertilizer to $\mathrm{CF}$ and FC treatments (see Figure 2). Error bars represent the s.d. of the average amoA copy number per g soil of triplicate QPCR reactions for each of three field replicates of each treatment. A complete summary of the statistical analysis of these data is shown in Supplementary Table S2. Ratios of AOA to AOB amoA copy number per $g$ soil are indicated for each treatment.

which was followed by significant increases in the AOA amoA gene copy numbers in both CF and LTF in Feb 2011. In CF, a non-significant upward trend in population size continued into Jun 2011. There were no significant changes in the AOA population of FC during the same period. The linear regression of AOA amoA gene copy number with NP or $\mathrm{RNP}_{\mathrm{AOA}}$ was non-significant in all treatments $\left(r^{2}=0.002-0.03\right)$.

$A O B$. AOB amoA gene copy abundance was greatest in all treatments in Apr 2010, with a trend for CF to contain the highest population. AOB amoA gene abundance subsequently declined throughout 2010 in the three treatments with the decrease becoming statistically significant in Oct 2010 for FC and LTF, and in Dec 2010 for CF (Supplementary Table S2). The lowest AOB amoA gene abundances were measured in Jan 2011, with no differences among 
the treatments $\left(2.0 \pm 1.4 \times 10^{6}\right.$ amoA copy numbers per g soil). After N fertilization of FC in Mar 2011, the AOB amoA abundance was significantly greater in Apr and May than in the non N-fertilized CF and LTF treatments, and the increase in AOB amoA abundance of FC coincided with a greater $\mathrm{RNP}_{\mathrm{AOB}}$ contribution to $\mathrm{RNP}_{\text {total }}$. The linear regression of AOB amoA abundance and NP was significant in CF $\left(r^{2}=0.5, P<0.001\right)$. In LTF, both NP and $\mathrm{RNP}_{\text {АОв }}$ were positively correlated with AOB amoA abundance $\left(r^{2}=0.3, P<0.001\right)$.

$A O A$ and $A O B$ community composition. MspI and $R s a \mathrm{I}$ digests of the archaeal amoA gene yielded seven and five distinct terminal restriction fragments (T-RFs), respectively. Multiple response permutation procedure analysis of the relative abundances of archaeal amoA gene T-RFs showed no significant effects among treatments $(P=0.217)$ or sampling times $(P=0.078)$ on the composition of the AOA population (Supplementary Figure S1). Terminal restriction fragment length polymorphism analysis detected nine and six distinct T-RFs from AluI and $C f o$ I digests of AOB amoA, respectively. Analysis of AOB amoA AluI and CfoI T-RFs showed significant treatment effects on the composition of the AOB population $(P \leqslant 0.0001)$, but no effect of sampling time $(P=0.6727)$. Non-metric multidimensional scaling ordination and multiple comparisons made between treatments showed that $\mathrm{CF}$ and FC were significantly different from LTF $(P \leqslant 0.001$, each). The relative total fluorescence of T-RF AluI200 (74\% of AluI T-RFs) and CfoI68 (86\% of $C f o$ I T-RFs) were significant biomarkers $(P \leqslant 0.05)$ for LTF soils, whereas T-RF distributions in $\mathrm{CF}$ and $\mathrm{FC}$ were more diverse with up to nine T-RFs detected and different distributions of AluI200, 220, 389 and 491 making up $80 \%$ of AluI T-RFs. CF and FC were also significantly different from each other $(P \leqslant 0.001)$, with AluI389 a significant indicator of soils collected from FC, and $C f o I 135$ a significant indicator of soils collected from $\mathrm{CF}$.

Because treatments had significantly different AOB community compositions, they were analyzed separately for effects of sampling time. In CF, there were no significant differences among sample times $(P=0.654)$. However, in FC May 2011 was significantly different $(P=0.017)$ from the other sample times with $C f o$ I135 identified as a significant indicator $(P=0.0032)$ of soil collected in May 2011. This coincided with the significantly higher AOB amoA gene abundance in post $\mathrm{N}$-fertilized FC than in CF or LTF. In LTF, there were significant differences between months $(P=0.008)$, primarily due to AluI491 being an indicator of samples collected in December. Restriction digests with TaqI showed that TaqI283 fragments made up $\geqslant 95 \%$ of the total relative fluorescence of all samples, indicating that $\mathrm{AOB}$ populations were dominated by Nitrosospira spp. (data not shown).

\section{Discussion}

By sampling intensively over a 15-month period, evidence was obtained for both cropping phase and seasonal effects on the soil NP, on the relative contributions of AOA and AOB to RNP, on the relative abundances of amoA gene copies of $\mathrm{AOA}$ and $\mathrm{AOB}$, and on $\mathrm{AOB}$ community composition. Although it is well documented that the ratio of AOA:AOB ranges widely in soils (Leininger et al., 2006; He et al., 2007; Adair and Schwartz, 2008; Shen et al., 2008; Schauss et al., 2009; Di et al., 2010; Wessen et al., 2010; Zeglin et al., 2011), no data exist on what might influence this ratio, or its dynamism. Our study showed that the AOA:AOB shifts were generated by a combination of different phenomena: (a) an increase in AOA amoA copy numbers in spring 2011 in CF and LTF, compared with their AOA counterparts in FC; (b) a larger population of AOB in spring 2011 under the $\mathrm{N}$-fertilized FC treatment compared with the AOB community under CF and LTF treatments; (c) better persistence of AOB between Apr and Oct 2010 in the CF treatment compared with $\mathrm{AOB}$ in both the FC and LTF treatments; (d) better overall persistence of AOA than AOB in 2010 in FC and LTF treatments.

These observations raise some interesting questions about the environmental drivers of AOA and AOB growth, as well as about their relative stress tolerances. In regards to growth, the increase in AOA amoA abundance that occurred in the fallowed phase of the CF treatment in the late winter/ early spring of 2011, was accompanied by a significant increase in NP, but not by any significant increase in the rates of $\mathrm{RNP}_{\mathrm{AOA}}$, nor by any significant change in the relative contributions of $\mathrm{AOA}$ and AOB to $\mathrm{RNP}_{\text {total }}$. It is possible this might reflect the limits of sensitivity of the RNP assay to measure statistically significant changes in the relative contributions of $\mathrm{AOA}$ and $\mathrm{AOB}$, but might also be supportive of the idea that ammonia oxidation is not the only energy-generating metabolism used by AOA for growth under some soil conditions (Jia and Conrad, 2009; Tourna et al., 2011). By contrast, in FC, the significant increase in NP after N fertilization in spring 2011 was accompanied by a significant increase in rates of both $\mathrm{RNP}_{\mathrm{AOB}}$ and $\mathrm{RNP}_{\mathrm{AOA}}$, but with $\mathrm{RNP}_{\mathrm{AOB}}$ making a greater relative contribution to $\mathrm{RNP}_{\text {total }}$, and an $\mathrm{AOB}$ amoA gene abundance that was significantly greater than in CF; however, there was no significant difference in AOA amoA gene abundance between treatments. In sum, our findings have identified soil treatments and seasonal conditions, where AOB and AOA activities respond differentially or synchronously, and that are either coupled or uncoupled from changes in their respective population sizes.

The different responses of AOA and AOB during the long interval of time in the wheat/fallow cycle where extractable $\mathrm{NH}_{4}^{+}$was at low levels serves to highlight our lack of knowledge of how AOA and 
AOB respond to the combination of soil stresses and $\mathrm{NH}_{4}^{+}$-limiting/starvation conditions under field conditions. There are a small number of publications spanning $>30$ years, which describe how AOB isolates respond to, and recover from $\mathrm{NH}_{4}^{+}$starvation under laboratory conditions. These studies showed that the viability of the marine AOB, Nitrosomonas cryotolerans, declined to $1-10 \%$ of the initial population after 25 weeks of $\mathrm{NH}_{4}^{+}$ starvation, (Johnstone and Jones, 1988a; Jones et al., 1988), which fits reasonably well with the 25- to 50-fold decline of the soil AOB populations that occurred over the 32-week period between Apr 2010 and Jan 2011. Additionally, $\mathrm{NH}_{4}^{+}$-starved $N$. europaea can immediately oxidize $\mathrm{NH}_{3}$ upon its reappearance and produce $a m o$ gene transcripts, but there is a delay in production of RuBisCo transcripts (Berube et al., 2007); and recovery of $\mathrm{CO}_{2}$-fixing activity of $\mathrm{NH}_{4}^{+}$-starved $N$. cryotolerans was delayed relative to $\mathrm{NH}_{3}$-oxidizing activity (Johnstone and Jones, 1988b). Furthermore, a substantial delay in recovery of $\mathrm{NH}_{3}$-oxidizing activity was caused by irreversible inactivation of AMO by acetylene in 10-day $\mathrm{NH}_{4}^{+}$-starved Nitrosospira briensis immediately prior to the addition of $\mathrm{NH}_{4}^{+}$(Bollmann et al., 2005), suggesting that de novo protein synthesis could be impaired by a relatively short period of $\mathrm{NH}_{4}^{+}$starvation. In this context, it is worth noting that the mean $\mathrm{RNP}_{\text {Aов }}$ was $\leqslant 0.4$ of $\mathrm{RNP}_{\text {total }}$ in 9 of 11 samples from the LTF treatment, which had not been fertilized for 20-21 years, and where NPs and RNPs were generally lower than most values measured in the cropping phases. As a consequence, we might speculate that whereas the soil-borne AOA communities maintained the biosynthetic capacity to resynthesize AMO and successfully perform RNP, many of the AOB communities from the same samples had diminished capacity. Whether or not this phenomenon should be regarded as a successful survival strategy by AOB in response to a prolonged period of $\mathrm{NH}_{4}^{+}$-limited conditions, or represents a deteriorating physiological state imminently associated with cell death awaits further investigation.

A final discussion point relates to the fact that the declines in AOB and AOA population densities of each of the three treatments during 2010 were not accompanied by any major shifts in community composition, thereby providing no evidence for differential resilience among the members of these communities to tolerate limiting $\mathrm{NH}_{4}^{+}$and seasonally induced soil stresses. From the alternate perspective, neither the significant increase of $\mathrm{RNP}_{\mathrm{AOA}}$ to fertilizer N (Apr 2011, FC) or the steady increase in AOA population density of CF in spring 2011, were accompanied by significant differences in archaeal amoA gene community composition between the three treatments, suggesting that AOA community composition was not controlled by $\mathrm{NH}_{4}^{+}$ availability or cultivation disturbance. In contrast, AOB amoA T-RFs shifted in ways that were consistent with $\mathrm{NH}_{4}^{+}$input driving community composition. For example, the T-RF CfoI135, which was significantly more abundant throughout 2010 in CF than FC and rare in LTF, increased in relative abundance in FC after fertilizer $\mathrm{N}$ addition. In addition, 20 years without fertilizer $\mathrm{N}$ applications or tillage has clearly resulted in a significant change in the AOB community of the LTF resulting in dominance by the T-RF AluI200 -a biomarker for Nitrosospira cluster 3a (Jia and Conrad, 2009; Mertens et al., 2009; Zeglin et al., 2011). This phylotype has been associated with low $\mathrm{N}$ fertility undisturbed soils, and contains members that are growth inhibited by high $\mathrm{NH}_{4}^{+}$levels. However, though the AOB community composition of LTF had changed, $\mathrm{RNP}_{\mathrm{AOA}}$ made the larger contribution to $\mathrm{RNP}_{\text {total }}$ in most of the LTF soil samples. Although it remains unclear if the shift in AOB composition has had any impact on the ability of AOB to compete with AOA, it is worth noting, that during May and Jun 2010 AOB contributed significantly to RNP, suggesting that the AOB community in LTF can be competitive with the AOA, even when extractable $\mathrm{NH}_{4}^{+}-\mathrm{N}$ exists $<10 \mu \mathrm{gg}^{-1}$ soil. Clearly, further work is needed to determine what controls the contributions of AOB and AOA to in situ soil nitrification, and to determine if certain phylotypes of AOB can compete effectively with AOA.

\section{Conflict of interest}

The authors declare no conflict of interest.

\section{Acknowledgements}

This research was funded by USDA CSREES Agreement No. 2007-35107-18355. Additional support obtained from the Oregon State University community included: technical services from the Central Analytical Laboratory, QPCR facilities at the Center for Genome Research and Biocomputing, and field sites maintained by the Hyslop Field Research Laboratory.

\section{References}

Adair KL, Schwartz E. (2008). Evidence that ammoniaoxidizing archaea are more abundant than ammoniaoxidizing bacteria in semiarid soils of northern Arizona, USA. Microbial Ecol 56: 420-426.

Berube PM, Samudrala R, Stahl DA. (2007). Transcription of all amoC copies is associated with recovery of Nitrosomonas europaea from ammonia starvation. J Bacteriol 189: 3935-3944.

Bollmann A, Schmidt I, Saunders AM, Nicolaisen MH. (2005). Influence of starvation on potential ammoniaoxidizing activity and amoA mRNA levels of Nitrosospira briensis. Appl Environ Microbiol 71: 1276-1282.

Boyle-Yarwood SA, Bottomley PJ, Myrold DD. (2008). Community composition of ammonia-oxidizing bacteria and archaea in soils under stands of red alder 
and Douglas fir in Oregon. Environ Microbiol 10: 2956-2965.

Di HJ, Cameron KC, Shen JP, Winefield CS, O’Callaghan M, Bowatte S et al. (2010). Ammonia-oxidizing bacteria and archaea grow under contrasting soil nitrogen conditions. FEMS Microbiol Ecol 72: 386-394.

Hallin S, Jones CM, Schloter M, Philippot L. (2009). Relationship between N-cycling communities and ecosystem functioning in a 50-year-old fertilization experiment. ISME J 3: 597-605.

He J-Z, Shen J-P, Zhang L-M, Zhu Y-G, Zheng Y-M, Xu M-G et al. (2007). Quantitative analyses of the abundance and composition of ammonia-oxidizing bacteria and ammonia-oxidizing archaea of a Chinese upland red soil under long-term fertilization practices. Environ Microbiol 9: 3152-3152.

Horz HP, Rotthauwe JH, Lukow T, Liesack W. (2000). Identification of major subgroups of ammonia-oxidizing bacteria in environmental samples by T-RFLP analysis of amoA PCR products. J Microbiol Methods 39: 197-204.

Jia ZJ, Conrad R. (2009). Bacteria rather than Archaea dominate microbial ammonia oxidation in an agricultural soil. Environ Microbiol 11: 1658-1671.

Johnstone BH, Jones RD. (1988a). Physiological effects of long-term energy-source deprivation on the survival of a marine chemolithotrophic ammonium-oxidizing bacterium. Marine Ecol -Progress Series 49: 295-303.

Johnstone BH, Jones RD. (1988b). Recovery of a marine chemolithotrophic ammonium-oxidizing bacterium from long-term energy-source deprivation. Canadian J Microbiol 34: 1347-1350.

Jones RD, Morita RY, Koops HP, Watson SW. (1988). A new marine ammonium-oxidizing bacterium, Nitrosomonas Cryotolerans Sp-Nov. Canadian J Microbiol 34: 1122-1128.

Leininger S, Urich T, Schloter M, Schwark L, Qi J, Nicol GW et al. (2006). Archaea predominate among ammonia-oxidizing prokaryotes in soils. Nature 442: 806-809.

McCune B, Mefford MJ. (1999). PC-ORD. Multivariate Analysis of Ecological Data. Version 4. MjM Software, Gleneden Beach, Oregon, USA.

Mertens J, Broos K, Wakelin SA, Kowalchuk GA, Springael D, Smolders E. (2009). Bacteria, not archaea, restore nitrification in a zinc-contaminated soil. ISME $J$ 3: 916-923.

Mintie AT, Heichen RS, Cromack K, Myrold DD, Bottomley PJ. (2003). Ammonia-oxidizing bacteria along meadow-to-forest transects in the Oregon cascade mountains. Appl Environ Microbiol 69: 3129-3136.

Norton JM. (2008). Nitrification in agricultural soils. In: Schepers JS, Raun WR (eds). Nitrogen in Agricultural Systems. American Society of Agronomy, Inc., Crop Science Society of America, Inc., Soil Science Society of America, Inc.: Madison, WI, pp 173-200.

Offre P, Prosser JI, Nicol GW. (2009). Growth of ammoniaoxidizing archaea in soil microcosms is inhibited by acetylene. FEMS Microbiol Ecol 70: 99-108.
Peterson RG, Calvin LD. (1996). Sampling. In Methods of Soil Analysis, Part 3- Chemical Methods. Sparks DL (ed). Soil Science Society of Ameria: Madison, Wisconsin, pp 1-18.

Rotthauwe JH, Witzel KP, Liesack W. (1997). The ammonia monooxygenase structural gene $a m o \mathrm{~A}$ as a functional marker: molecular fine-scale analysis of natural ammonia-oxidizing populations. Appl Environ Microbiol 63: 4704-4712.

Schauss K, Focks A, Leininger S, Kotzerke A, Heuer H, Thiele-Bruhn S et al. (2009). Dynamics and functional relevance of ammonia-oxidizing archaea in two agricultural soils. Environ Microbiol 11: 446-456.

Shen JP, Zhang LM, Zhu YG, Zhang JB, He JZ. (2008). Abundance and composition of ammonia-oxidizing bacteria and ammonia-oxidizing archaea communities of an alkaline sandy loam. Environ Microbiol 10: 1601-1611.

Shi W, Miller BE, Stark JM, Norton JM. (2004). Microbial nitrogen transformations in response to treated dairy waste in agricultural soils. Soil Sci Soc America J 68: 1867-1874.

Taylor AE, Zeglin LH, Dooley S, Myrold DD, Bottomley PJ. (2010). Evidence for different contributions of archaea and bacteria to the ammonia-oxidizing potential of diverse Oregon soils. Appl Environ Microbiol 76: 7691-7698.

Tourna M, Freitag TE, Nicol GW, Prosser JI. (2008). Growth, activity and temperature responses of ammonia-oxidizing archaea and bacteria in soil microcosms. Environ Microbiol 10: 1357-1364.

Tourna M, Stieglmeier M, Spang A, Konneke M, Schintlmeister A, Urich $\mathrm{T}$ et al. (2011). Nitrososphaera viennensis, an ammonia oxidizing archaeon from soil. Proc Natl Acad Sci USA 108: 8420-8425.

Verhamme DT, Prosser JI, Nicol GW. (2011). Ammonia concentration determines differential growth of ammonia-oxidising archaea and bacteria in soil microcosms. ISME J 5: 1067-1071.

Wessen E, Nyberg K, Jansson JK, Hallin S. (2010). Responses of bacterial and archaeal ammonia oxidizers to soil organic and fertilizer amendments under long-term management. Appl Soil Ecol 45: 193-200.

Wessen E, Soderstrom M, Stenberg M, Bru D, Hellman M, Welsh A et al. (2011). Spatial distribution of ammoniaoxidizing bacteria and archaea across a 44-hectare farm related to ecosystem functioning. ISME $J \mathbf{5}$ : 1213-1225.

Xia W, Zhang C, Zeng X, Feng Y, Weng J, Lin X et al. (2011). Autotrophic growth of nitrifying community in an agricultural soil. ISME I 5: 1226-1236.

Zeglin L, Taylor AE, Bottomley PJ, Myrold DD. (2011). Bacterial and archaeal amoA gene distribution covaries with soil nitrification properties across a range of land uses. Environ Microbiol Reports 3: 717-726.

Zhang LM, Offre PR, He JZ, Verhamme DT, Nicol GW, Prosser JI. (2010). Autotrophic ammonia oxidation by soil thaumarchaea. Proc Natl Acad Sci USA 107: 17240-17245.

Supplementary Information accompanies the paper on The ISME Journal website (http://www.nature.com/ismej) 